\title{
10 The Tree of Nosology in Tibetan medicine
}

\author{
Katharina Sabernig
}

\section{Introduction}

The most authoritative Tibetan medical text is known as the Four Treatises (Rgyud bzhi $),{ }^{1}$ dated to the twelfth century and commonly associated with the authorship of Yuthok Yonten Gonpo (G.yu-thog Yon-tan-mgon-po). Similar to the classical Chinese medical text Inner Canon of the Yellow Emperor (Huangdi neijing) and typical for the style of Indian sūtras, each chapter of the text is embedded in a poetic dialogue. While the Chinese classic is based on a dialogue of questions and answers between the Yellow Emperor Huang Di and his six ministers (Nguyen Van Nghi 1996-97: 27; Unschuld and Tessenow 2011), the setting of the Tibetan Four Treatises rests upon a dialogue between the sage Rigpa Yeshe (drang srong Rig-pavi-ye-shes), a manifestation of the Buddha Sākyamuni and the sage Manasija (drang srong Yid-las-skyes). With regard to the medical content, many parallels may be found in the Sanskrit text Aștāinga-hrdaya-samhitā or even in older, so-called pre-Aștāinga texts, such as the Suśruta-samhitā (Priya Vrat Sharma 2000; Yang Ga 2010). Ronit Yoeli-Tlalim (2010: 198, 204) found passages in the early Tibetan text she translated as Medical Method of the Lunar King (Sman dpyad zla bavi rgyal po) showing similarities to the Canon of Medicine (al-Qānūn fì t-Tibb), which was made famous by Abū 'Alī al-Husayn ibn 'Abd Allāh ibn Sīnā, better known to the Western world as Avicenna, the Latin equivalent of Ibn Sīnā (972-1036). His influential work could not have been compiled without earlier translations of medical knowledge from Greek to Arabic by Abū Zaid Hunan ibn Ishạa al- 'Ibādī (Latinised Iohannitius, 808-73?), whose work Questions on Medicine, preserved in Syriac and Arabic, consists of important medical questions and their respective answers (Wilson and Dinkha 2010).

These possible influences are not surprising. Politically, Tibet is today part of the Peoples' Republic of China (PRC), situated between South, North and East Asia, not far away from East Mediterranean regions which constitute Western Asia. Historically, cultural exchange took place with all neighbouring cultures. The seventh and eighth centuries of the first millennium mark an important time for the development of Tibetan medicine. According to Tibetan historical writings, Emperor Songtsen Gampo (Srong-btsan-sgam-po, died $650 \mathrm{CE}$ ) invited physicians from India, China and Persia to his court, and Chinese princesses brought 


\section{Katharina Sabernig}

medical texts to Tibet through marriage as part of their dowries (Taube 1981: 10). The classical sources inform us that a physician from Persia or even Byzantium visited the court: his name was Galenos (Ga-le-nos), obviously a representative of the old Greek medical tradition known by the name 'Byzantine medicine'. The most famous name associated with this medical tradition is without doubt Galen of Pergamon - a physician, surgeon and anatomist who lived in the second century (ca. 130-200 CE). The person of 'Galenos' mentioned in the Tibetan sources was certainly not the 'real' Galen, but must be regarded as a representative of the medical tradition going back to him.

Yang Ga's summary of the historical discussion on the foreign physicians in the classical Tibetan sources sheds light on the way the information was acquired: 'The Indian physician Bhwa ra Dhwa dza (Bharadvāja), the Chinese physician Hen wen hang de (Xuanyuan huangdi), and the Stag gzig or Khrom Physician Ga le nos were invited into Tibet' (Yang Ga 2010: 38). It is still under discussion where to exactly locate Stag-gzig or Khrom. Generally speaking, Stag-gzig is associated with Persian areas and Khrom with areas formerly belonging to the eastern Roman empire (Yoeli-Tlalim 2010: 195-7). It should be noted that Xuanyuan huangdi is the same figure as the most prominent role in the Huangdi neijing, namely the Yellow Emperor. Bharadvāja is one of the Vedic sages mentioned in the Rgveda and famous for his medical knowledge. Although there might have been physicians at court representing these medical traditions, the names must have been chosen symbolically to represent major medical traditions.

Under the aegis of Emperor Trisong Detsen (Khri-srong-lde-btsan, 755-97), scholars from India, Kashmir, Nepal, Dolpo, China, Iran and the Turkic regions of Central Asia were invited (Taube 1981: 13; Meyer 1995: 110; Yang Ga 2010: 35-43). Situated in the middle of the trade route between India and China, Tibet was important not only for the exchange of medical knowledge but also for contacts with Arab and Jewish traders (Yoeli-Tlalim 2013: 54). Because of these early influences, Tibetan medicine may be regarded as an example of medical pluralism, a conglomerate of different historically grown ethno-medical systems, including Tibet's own medical traditions. From the beginning of the second millennium CE until the beginning of the seventeenth century CE, Tibetan medicine developed in multiple places, visible in the formation of native Tibetan medical texts, and different schools of interpretation of the Four Treatises arose (Blezer et al. 2007).

Before going into detail, some fundamental principles of Tibetan medicine which have some connections to other medical systems shall be introduced briefly. The basic principle of bodily formation in Tibetan medicine is the concept of the 'five elements' (vbyung ba lnga), while the major disease-related principle is the concept of the 'three humours' (nyes pa gsum). ${ }^{2}$

The five elements form the basis for theories of life, nature and growth, and they play an important role in astrology, embryology and thanatology. They are connected to the seasons, the movement of planets, Buddhist rituals, divination techniques and medicinal processes such as uroscopy or sphygmology (e.g. YoeliTlalim 2010; Parfionovitch et al. 1992). According to Tibetan medicine, the five 
elements play an important role in the metabolism of food and medicines, where they are associated with the formation of taste, the essential pharmacodynamic concept in Tibetan medicine. Therefore, they form the foundation of any prevention and therapy. However, with regard to the classification of diseases, they play only a tangential role, whereas the 'humours' play a rather essential role.

Nevertheless, while the five elements work reliably in the background, their medical value becomes more obvious if we take a look at the surrounding medical cultures. Due to its complex history, Tibetan medical theory includes the Chinese as well as the Indian system of the five elements. The Indian system of Ayurveda involves earth, water, fire, air and space; the most prominent system in traditional Chinese medicine uses earth, metal, water, wood and fire. If we move a bit more westward, we find another medical system that employs elements as the basic theory as well. In ancient Greek medicine we find fire, earth, water and wind, and sometimes even a further property which includes space. Aristotle connected to each of the elements a basic movement where earth and water move 'downward' and air and fire move 'upward' (Krafft 2006). In Tibetan pharmacology, the downward movement of earth and water is used to create laxatives and the upward movement of air and fire is the basis for emetics (Parfionovitch et al. 1992: 217 no. 14+15). The Greek concepts of the humours developed in the time of Hippocrates, who lived in the fourth century BCE, and was reformed and systematised by Galen of Pergamon in the second century CE. This system is also used in Islamic medicine in the Middle East and Muslim India, where it is called Unani (from Arabic yūnānì) medicine, standing for 'Ionian' or Greek and thus referring back to this medical tradition (Liebeskind 1995: 39). The beginnings of a similar system, though involving a tighter relation to inner organs, can be found in Mesopotamian medicine (Steinert 2016: 239).

The second important concept in Tibetan medicine is that of the 'three humours'. These are rlung, commonly translated as 'wind', mkhris pa 'bile' and bad kan 'phlegm'. At a religious level they are related to the three so-called mental poisons of Buddhism - desire (vdod chags), hatred (zhe sdang) and delusion ( gti mug) which constitute the primary causes of diseases (nad kyi rgyu). Aside from this connection to the religious superstructure, wind, bile and phlegm have various functions. Generally, wind is associated with any kind of movement, bile with forms of transformation and phlegm with the ability to stabilise. For example, certain forms of wind in the body are responsible for ascending, for forming the voice, for downward movements such as excretion of faeces or for the power of giving birth. Examples for the physiological function of bile are its digestive power and the 'clearing' of sight and complexion. Phlegm is credited with a physically supportive function and is regarded as responsible for the gustatory sense or, psychologically, for the ability to be satisfied.

The theory of the three humours is not originally Tibetan, as it forms the core concept of Āyurveda in India. Here the three humours are called kapha, pitta and $v \bar{a} t a$, corresponding to 'phlegm', 'bile' and 'wind'. Although there exist some differences in detail, it is obvious that the Indian and Tibetan systems of the three humours are related to each other. In Muslim Unani medicine and ancient Greek 
medicine, there exists another, very similar humoral system which is strongly connected to the elements mentioned earlier. In this system we find four humours:

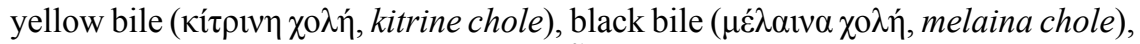

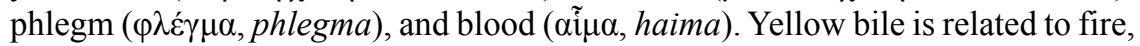
black bile to earth, phlegm to water and blood to air. The word humour, which we use in the context of different ethno-medical systems, is derived from Greek chymoi ( $\chi 0 \mu$ oí, lat. humores), referring to something liquid. According to this medical system, one is healthy if these four humours are balanced (eucrasia, from

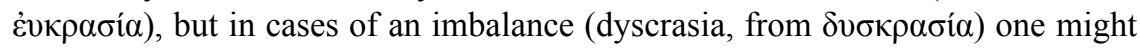
become ill. A disease caused by such an imbalance is called humoral pathology (see Nutton 2002, 2006; Eckart 2005: 29).

The connection between the five elements and the three humours in Tibetan medicine and Āyurveda is not as obvious as in ancient Greek medicine. In the former systems, two elements create one humour: space and air create wind, earth and water create phlegm, and water and fire create bile. The role of water is discussed controversially because bile is mainly hot in nature. In traditional Chinese medicine, the connection between elements and humours differs again. Here, the so-called humours are 'blood' (xue, 血) and $q i$ (气), the latter of which stands for a principle that is difficult to translate but may best be described as 'breath' of 'life energy'. Blood and $q i$ are the major principles circulating in the body. There exist various connections and interactions of these humours with the five elements and the inner organs, which are divided into solid and hollow viscera, named in Chinese metaphorically 'depot' (zang 脏) and 'palace' ( $f u$ 腑) The five 'depots' or 'solid viscera' are lung, heart, spleen, liver and kidney(s); the six 'palaces' or 'hollow viscera' are small and large intestine, stomach, gall- and urinary bladder and the morphologically not identifiable organ 'triple burner' (san jiao 三焦; for uncertainties with regard to translations, see Unschuld and Tessenow 2011: 16). Generally, the organs were not conceived anatomically but rather seen as configurations of sympathetic powers (Kuriyama 1999: 265-6). These organs are assigned in pairs to the five elements. For example, gallbladder and liver are assigned to the element 'wood' and the lung and large intestine are assigned to the element 'metal'. The same pairs of internal viscera can be found in Tibetan medicine, too (Bolsokhoeva 2016: 12-13). However, in the Korean 'Sasang Constitutional Medicine', a similar system associated with inner organs was created in East Asia.

The four different temperaments derived from Greek medicine can be classified clearly: choleric (yellow bile), melancholic (black bile), phlegmatic (phlegm) or sanguine (blood). These are connected to the elements fire, earth, water and air, respectively. The names of these still well-known temperaments refer directly to the humours. ${ }^{3}$ Interestingly, various traditional theories of Asian medicines associate problems attributed to bile with a choleric mood or bad temper. In traditional Chinese medicine, the emotion associated with the liver ( $g a n$ 肝) is anger ( $n u$ 怒), and bile (dan 胆) is a synonym for courage (Lorenzen and Noll 1992). In Tibetan medicine, bile is associated with the Buddhist mental poison hatred, but also with a sharp mind (blo rno ba). 
Within all these systems a special polarity is apparent: the polarity of fire and water or hot and cold. It is also crucial for the concept of yin and yang (yinyang 阴阳) in traditional Chinese medicine, and the polarity between hot and cold is fundamental in Tibetan medicine, too. At the end of the chapter on physiology and pathology of the Root Treatise it is stated that pathologies associated with wind and phlegm are associated with cold (grang $b a$ ) as is water, whereas blood and bile are hot (tsha ba) like fire (Bstan-vdzin-don-grub 2005-08: 14/1-2; Ploberger 2012: 102; cf. Parfionovitch et al. 1992: 19). Notably in this case, a fourth humour is included: blood, an important humour in Galenic medicine. The concept of the three nyes pa is central in Tibetan medical practice, but as the Tree of Nosology demonstrates further in the following, Tibetan nosology includes various other categories of pathological conditions.

\section{The structure of the Four Treatises}

The composition of the Four Treatises (Rgyud bzhi) consists of four parts, each of which deals with the eight traditional subject areas (eight branches) of Tibetan medicine in different ways: (1) the Root Treatise (Rtsa rgyud) provides a general overview of the medical skills, such as a basic knowledge of physiology, pathology, diagnostics and therapeutic intervention; (2) the Explanatory Treatise (Bshad rgyud) provides the theoretical foundations and as a section could also be called preclinical; (3) the Instructional Treatise (Man ngag rgyud) treats the clinical aspects of the eight subject areas, including a description of particular diseases; and (4) the Subsequent Treatise (Phyi ma rgyud) provides deepening views on urine and pulse diagnostics, medicinal preparations, and various forms of external applications (Gyurme Dorje 1992: 14-15). ${ }^{4}$

The eight subject areas may be regarded as traditional medical specialties, although modern biomedicine certainly has its own categories. A traditional Tibetan physician used to be well versed in each of the fields: (1) lus, literally 'body', involves general and internal medicine; (2) byis pa 'paediatrics'; (3) mo nad 'gynaecology'; (4) gdon 'demonic influences', corresponding more or less to psychiatry; (5) mtshon, injuries or surgical wound care; (6) dug 'poisoning', including atmospheric disturbances; (7) rgas ba 'age', dealing with geriatrics and rejuvenation; and (8) ro tsa 'infertility'.

The architecture of the Four Treatises is well designed and remained stable over centuries, although different schools of interpretation created different commentaries. Until the late seventeenth century there existed hardly any visual representations - or at least if there were some, they are not available now. Under the reign of the Fifth Dalai Lama and his Regent Sangye Gyatso (Sangs-rgyasrgya-mtsho, 1653-1705), the situation changed fundamentally. This period is characterised by the unification of Tibetan regions and the centralisation of political and religious power. This framework facilitated the development and the institutionalisation of Tibetan medicine, which is why this era is also known as the 'Golden Century of Tibetan Medicine' (Meyer 2003). The fruitful time resulted in the establishment of a medical college on the prominent hill just opposite the 
Potala Palace, and a set of 77 elaborated thangka paintings illustrating the famous Blue Beryl commentary to the Four Treatises was commissioned. ${ }^{5}$

\section{Arboreal metaphor}

The arboreal metaphor in the form of an 'unfolded tree' (sdong vgrems) not only is used to visualise the concept of nosology but is also the theme of the sixth chapter of the Root Treatise. There it describes and classifies the contents of the three preceding chapters by means of a tree metaphor: chapter three on physiology and pathology, chapter four on diagnostics and chapter five on therapeutic intervention. Three thangkas of the illustrations to the Blue Beryl visualise the tree metaphors of these chapters. Before going into detail concerning the role of the arboreal metaphor in Tibetan medical culture, I would like to provide a brief overview of the general use of tree hierarchies.

Structuring content by means of an unfolded tree is not a specifically Tibetan phenomenon. Just to give a few examples: Christian representations of the seven deadly sins were presented in form of trees (Jacob-Friesen 2007: 54); the Twelve Apostles were also depicted in this fashion. Genealogical trees of European royal houses are quite commonly known; even a genealogical tree of the Prophet Mohammed leading back to Abraham and the forefathers is attested (Van Bussel and Steinmann 2011: 112-19). Tree structures and diagrams are also common in computer sciences and used in designing websites or so-called mind maps. Especially in biology and linguistics, they are often used to visually organise information (for genealogical trees of languages, cf. Militarev 2010: 258-9).

The useful visual organisation of information is not the only reason for the popularity of tree diagrams in Tibet. The worshipping of trees is a widespread phenomenon, and in the case of Tibetan Buddhism, the tree still has another significance: Siddhārtha Gautama reached his enlightenment under the Bodhi tree and thus became a Buddha. Thus, a miraculous tree in Kumbum Monastery is said to have grown at the place where the placenta had fallen to the ground after the birth of the great reformer of Tibetan Buddhism, Tsongkhapa Lozang Drakpa (Tsong-kha-pa Blo-bzang-grags-pa, 1357-1419). Another example for the use of the unfolded tree metaphor is the clearly structured information on the Tibetan grammar (Bkra-shis-dpal-ldan 1985; Sabernig 2017: 57). Furthermore, Buryat scholars illustrated their lineage histories through trees (Tsyrempilov and Vanchikova 2004: xi), and Olaf Czaja has published widely ramified trees on the genealogy of Tibetan noble families (Czaja 2013). These few examples may be sufficient to show that the tree metaphor is widespread in the Tibetan cultural area. The origin of the use of the unfolded tree in Tibetan medicine is unknown, but it would not be surprising if the idea had been adopted from Eastern Mediterranean medical traditions where the metaphor was common in medieval Islamic medicine (Pormann and Savage-Smith 2007). And there is evidence that in the ninth century branch diagrams were used in Arabic treatises, possibly continuing a now lost Alexandrian tradition (Savage-Smith 2002: 122). 
The use of a symbolic tree to organise content can be found frequently in the history of medicine. A beautiful example is the Isagoge by Iohannitius (Abū Zaid Ḥunan ibn Ishạāq al- 'Ibādī), referring to Hippocratic medicine (Demaitre 2012: 22-5) and its branch diagrams as a mnemonic device to divide and subdivide a text to remember it more easily. They are also related to Galenic treatises, which were translated into Syriac, Arabic, Hebrew and Armenian (Nutton 2002: vii; Pormann and Savage-Smith 2007: 14). According to Savage-Smith, the origin of such branch diagrams in Galen's treatise on materia medica (De simplicum medicamentorum, preserved in a twelfth or early thirteenth-century manuscript now in the Bodleian Library), called tashjir in Arabic, is a matter of speculation: 'that is, whether it was a didactic tool originating in Alexandria in Late Antiquity or whether it arose in the Islamic context' (Savage-Smith 2002: 122). The Codex Vindobonensis medicus graecus, a manuscript dated to the thirteenth to fifteenth century held in the Austrian National Library, contains schematic representations to ten Galenic treatises (Gundert 1998). In post-medieval Europe, arboreal schemes were used to classify medical knowledge, too. An elaborate visual form of a new systematology of dermatological diseases was constructed by Jean Louis Alibert in 1835, in which the trunk represents the skin in general and the ramifying branches classify species, subspecies and varieties of dermatological manifestations (Ehring 1989: 107-8). Another example is a tree graphic entitled Army Medical Library, in which the branches of the tree symbolise the major medical fields collected in the renamed U.S. National Library of Medicine (Sappol 2012: 6-7). Even the most recent nosological system of the International Classification of Diseases (ICD 10) maintained by the World Health Organisation (WHO) is arranged in an alphanumerical notation of widely ramifying hierarchies of diseases - a form of data structure commonly referred to as 'tree structure'. In the case of some diseases mentioned in the nosological chapter of the Explanatory Treatise, I will refer to the ICD 10 system.

In the hagiography of Yuthok Yonten Gonpo, to whom the Four Treatises are attributed, we find that he had obtained teachings on two 'unfolded trees' of the first two volumes of the Four Treatises in Oḍịāna, a legendary early medieval place in India which is located in the Swat District of today's Pakistan. Whereas in this text the explanation of the first tree is clearly connected to the description in the Root Treatise, the story continues that Yuthok Yonten Gonpo received teachings by Padmasambhava (Pad-ma-vbyung-gnas), including a detailed analysis of the Explanatory Treatise in the form of a Bodhi tree with 720 leaves (Jampal Kunzang 1973: 285-6). Unfortunately, the text does not give any information on the content symbolised by these leaves. However, the story is more interesting with regard to its symbolic message rather than with regard to a historical relation between Yuthok Yonten Gonpo and his teacher Padmasambhava: while in the Four Treatises it is the healing manifestation of the Buddha Sākyamuni who is teaching medicine to a sage, here it is a spiritual master teaching a Tibetan scholar.

Fernand Meyer refers to a comment by Sangye Gyatso which reveals that he had envisaged the arboreal organisation of the contents of the much more 
comprehensive chapters of the Explanatory Treatise, but feared ending up with a scheme that was too complex to be visualised (Meyer 1992: 9). Maybe as a result of these considerations Lozang Chödrak (Blo-bzang-chos-grags, 1638-1712?), the personal physician of the Fifth Dalai Lama, created the text Clear Essay to the Unfolded Trees to the Explanatory Treatise with the catchy title Golden Spoon (Bshad rgyud kyi sdong vgrems legs bshad gser gyi thur ma), which organised the content of the Explanatory Treatise by means of tree metaphors (Blo-bzangchos-grags 2005). ${ }^{6}$ To give an idea of the quantitative dimensions: while the three metaphorical trees of the Root Treatise consist of 9 trunks, 47 branches and 224 leaves, the 34 roots of the Explanatory Treatise structure the content with the help of 78 trunks, 385 branches and thousands of leaves. The elaborate work of the surgeon, anatomist and medical teacher also renowned as Darmo Menrampa (dar mo sman rams pa) - he was a physician from Darmo - was visually implemented in the form of 19 murals in the inner courtyard of the Medical College of Labrang Monastery, situated in present-day Gansu province of China.

The structure of each of the 31 chapters of the Explanatory Treatise is depicted by a hierarchic tree model that structures the contents of subchapters, including specific medical items such as symptoms, diseases, medicines or diagnostic techniques, which are each symbolised by leaves. The conversion of such an extensive amount of written information into an image was only possible because the authorities of the Medical College at Labrang Monastery resorted to a skilful device: they used leaves of different shapes to encode different quantities. For example, a five-fingered green leaf stands for a single item; a narrow, slightly feathered leaf stands for ten items; and a colourless, wavy leaf for a hundred units. Some trees even carry leaves with symbolic numbers to represent the amount of body pores or hairs. With the help of such visual tools it became feasible to depict a huge quantity of information which medical students traditionally had to learn by heart. ${ }^{7}$ Similar to the style of the thangka illustrations to the Blue Beryl, one of the Labrang trees bears not only green leaves, but also yellow, white and blue leaves, the latter of which represent the three humours. The trees on the murals are only labelled up to the branches. The meaning of the leaves is not obvious for medical laymen, but with the help of Lozang Chödrak's text it becomes possible to identify the definition of every single leaf. ${ }^{8}$

Other elaborate visual representations of the Explanatory Treatise in the form of unfolded trees similar to those presented in the medical faculty at Labrang Monastery are not yet known. Even the painter of the murals, Nyingchak Jamzer (Snying-lcags-byams-zer, born 1950), with whom I conducted an interview, was not aware of any other visual representation of Lozang Chödrak's text (Sabernig 2017: 90). In the meantime, the murals have also aroused interest in China, and the images where published together with Lozang Chödrak's text and a Chinese translation (Blo-bzang-chos-grags 2017).

Before I came across the publication of Lozang Chödrak, I considered other texts to find the written basis for the murals. For instance, the eminent physician and teacher Khyenrap Norbu (Mkhyen-rab-nor-bu, 1883-1962) has written an impressive treatise in which he structured the chapters of all parts of the Four 
Treatises in the form of unfolded trees. The edited publication (Mkhyen-rab-norbu and Byams-pa-phrin-las 1987) comprises many illustrations of the content in sketch-like fashion; however, it includes almost no representations on the Explanatory Treatise. The corresponding contents of this work are similar to Lozang Chödrak's text but by no means identical. It is likely that Khyenrap Norbu based his treatise on Lozang Chödrak's work, but both scholars might also have known a work of the sixteenth-century Buddhist scholar Losel Wangpo Péma Karpo (1527-92?) (Pad-ma-dkar-po [Blo-gsal-dbang-po] 2007). In his Commentary to the Four Treatises: A Treasure of Benefits for Others, Péma Karpo described the contents of the first three treatises by means of branches and leaves. Even though the descriptions go far beyond the structuring of chapter headings, they do not do justice to the complexity of the Explanatory Treatise and cannot be regarded as a literary source, but possibly as a stimulating precursor for Lozang Chödrak's work. Tsangmen Yeshé Zangpo (Gtsang-sman Ye-shes-bzang-po, 1707-85?), the founder of the medical faculty at Labrang Monastery, also taught the tree metaphor (Ye-shes-bzang-po [Gtsang-sman] 2007), but his remarks do not match the complex explanations of Lozang Chödrak, although he probably knew his work.

In recent times, it has become fashionable to use tree metaphors in publications of Tibetan medicine, and it is still a part of the vivid medical culture of the region. A larger wall painting in the front yard of the new hospital for Tibetan medicine in the nearby village of Xiahe outside the monastery of Labrang is worth mentioning. It shows several unfolded trees, which sketch simplified structures to give an overview of all four parts of the Four Treatises, but they symbolise far less detail than the murals at Labrang Monastery. Similar trees, like those presented at the new hospital in Xiahe, can be found in the old institute of medicine and astrology in Lhasa.

The didactic principle of unfolded trees has been widely used in the medical curriculum. It is used as a didactic tool to explain the content of the teachings, as a mnemonic device and during examinations to present learned knowledge (Gerl and Aschoff 2005: 122, 128, 152.) There is no doubt that both thangka illustrations to the Blue Beryl and wall paintings were applied as didactic material in the classical training. The extent to which the thangkas were actually used for teaching has still not been clarified, but it is known that on certain days of the year they were exhibited and presented to a wider public (Meyer 1992: 12). Several physicians who were educated in Tibetan medicine in Amdo (north-eastern Tibet) told me that they were taught in small groups with the aid of the tree metaphor. Some of them even created paintings themselves. An elderly monkphysician remembered that one of his teachers used wooden sticks and added small stones to present relevant content. This practice is also documented by a manuscript catalogued by Dieter Schuh (Schuh 1973: 85; Manuscript of the Staatsbibliothek zu Berlin, shelf number: Hs. sim. or. JS 151 [81]; see Figure 10.1). In the Medical College at Labrang Monastery, I was shown green five-fingered plastic leaves designed on the basis of the painted leaves on the murals, which were grouped around wooden sticks and flowers to explain the unfolded trees more vividly. 


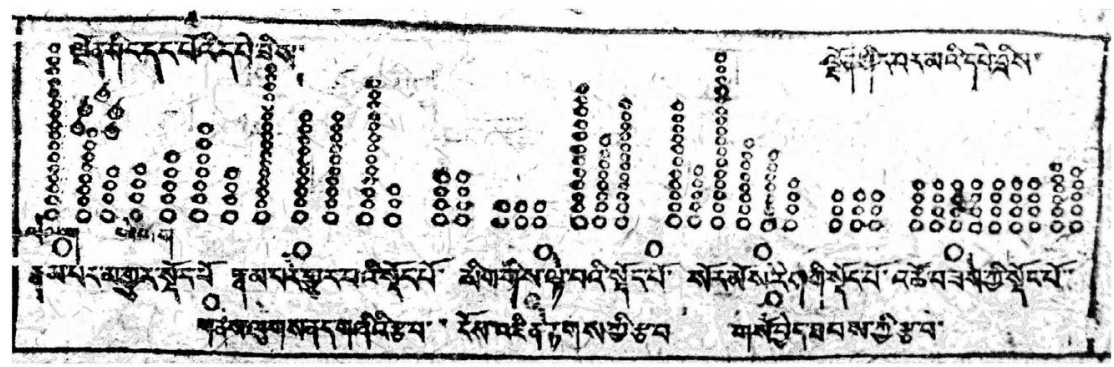

Figure 10.1 Staatsbibliothek zu Berlin - Preußischer Kulturbesitz, Orientabteilung, Signatur: Hs. sim. or. JS 151 (81)

\section{Illness and classifications of diseases in the Four Treatises}

Various aspects of aetiology, pathogenesis and nosology are explained in all of the Four Treatises, whose contents have remained relatively stable in the course of time. The third chapter of the Root Treatise provides the basic concepts in the field of pathology at the most elementary level. This part of the text indicates the underlying primary causes of diseases (nad kyi rgyu) being connected to the three mental poisons of Buddhism - desire, hatred and delusion. The chapter also gives brief information on trigger factors or secondary causes (nad kyi rkyen) such as time (dus), demons (gdon), diet (zas) and behaviour (spyod pa) and describes the vulnerability of the body with regard to the age of the patient, modes of entry of a disease and predominant localisations of the pathogenic humours. Even incurable conditions, literally 'fruits' or 'results' (vbras bu), and secondary dyscrasia induced by the treatment of a primary humoral pathology are mentioned.

The sections on pathology in the Explanatory Treatise comprise five chapters. Each gives detailed information on topics touched only superficially in the Root Treatise. They present knowledge on the primary causes of diseases (nad kyi rgyu), on trigger factors (nad kyi rkyen), mode of entry (nad vjug tshul), characteristics of the diseases (nad kyi mtshan nyid) and classification of diseases (nad kyi dbye ba). The latter forms the basis for the Tree of Nosology, which is the focus of this chapter, and whose widely ramified hierarchy will be described in more detail later. The chapter on the primary causes of diseases expands the connections between the three poisons of Buddhism and the three humoral conditions. The chapter contains the basis for the aetiology of diseases, whereas the chapter on the trigger factors may be regarded as the fundament of Tibetan pathogenesis, which is divided into three aspects of the development of a disease in terms of humoral pathologies: (1) growing and spreading (skye mched); (2) latent maturation (i.e. accumulation as well as aggravation - gsog ldang); and (3) manifestation (slong rkyen). The chapter on the mode of entry is divided into a rather abstract part explaining how pathogenic factors invade the body - as arrows hit the target - and into a descriptive part which lists specific locations in 
the body associated with the three humours. The chapter on the characteristics of the diseases gives information on general signs and symptoms with regard to an excess or deficiency of the three humours, bodily constituents (lus zungs), and waste products (dri $m a)$.

The Instructional Treatise is roughly based on the chapter on the classification of diseases in the Explanatory Treatise. In contrast to the Explanatory Treatise, where just groups of diseases and some individual names are listed, the much more extensive Instructional Treatise presents each of the individual diseases with regard to the primary causes, trigger factors, classification (dbye ba), signs and symptoms (rtags) and the respective remedy (bcos thabs). Finally, the Subsequent Treatise deepens various aspects of the diagnostic and therapeutic skills.

\section{The Tree of Nosology}

The Labrang mural ${ }^{9}$ depicts the complete hierarchical tree structure of the twelfth chapter of the Explanatory Treatise on the classification of diseases (see Figure 10.2). The labels on the mural are given in translation in this chapter's appendix, which follows. In contrast to this elaborated visual aid, the illustrations to the Blue Beryl depict the contents of this complex chapter just marginally in the form of a single line in thangka no. 19 (Parfionovitch et al. 1992: 53 no. 104-15). The Tree of Nosology is based on a descriptive text, but the visual representation demonstrates the structural complexity in a much more understandable fashion. Only the trees organising the chapters on anatomical knowledge (lus gyi gnas lugs) and the practising physician (bya ba byed pa sman pa) have more branches. It must be noted that Lozang Chödrak did not only organise the given information in the Explanatory Treatise but also lists all names of diseases or special forms of pathologies where the Explanatory Treatise often just mentions the number of different types of diseases. Based on the description of Lozang Chödrak's text, the huge tree comprises one root (rtsa ba), three trunks (sdong po), forty-three branches $(y a l g a)$ and hundreds of leaves (lo $m a)$. The division into three trunks provides the conceptual frame for the classification of diseases. The left trunk (I) defines the 'cause' (rgyu) of diseases from a rather religious perspective, differentiating between causes connected to this lifetime (I.1) in contrast to causes accumulated in a former life (I.2) or a mixture of both (I.3). The central trunk (II) gives the 'basis' (rten) of the medical classification and is the focus of the following explanation. The right trunk (III) demonstrates with three branches philosophically the variety of appearances of individual pathologies or types. The first branch demonstrates numeric aspects such as the possibilities to combine nyes pas (the three humours), bodily constituents, various forms of dyscrasias and disease signs (rnam pa; III.1). The second one summarises the meaning of the chapter in a nutshell (III.2) and the third one refers to the individual meaning with regard to the stage of a disease: reason, prodromal, manifestation of signs and full clinical picture of a disease (III.3). It is not in the scope of this chapter to describe all the details, as they can be found in the respective translations, but this chapter will aim to demonstrate different levels of classification visualised through the tree. 


\section{Katharina Sabernig}

The trunk of the basis of medical classification (II) represents more than threequarters of information comprising the whole chapter. It divides diseases into five types associated with different patient groups: men (skyes pa; II.1), women (bud med; II.2), children (byis pa; II.3) and elderly people (rgas pa; II.4), but the fifth and largest group represents widespread, general diseases (kun khyab thun mong; II.5), each of which is symbolised by a leaf. While the gender and age-related classes are each described in detail with several chapters in the Instructional Treatise, the classification of the widespread, general diseases partially follows a different logic.

These widespread pathologic conditions are classified with the aid of five further ramifying branches, four of which explain the subcategories of the 404 diseases of Buddhist medicine. The division into $4 \times 101$ different diseases is made with regard to humours (nyes pa; II.5.1), main [classification] (gtso bo; II.5.2), localisation (gnas; II.5.3) and type (rigs; II.5.4). Finally, the fifth and final branch (mjug bsdu pa; II.5.5) differentiates each of the 404 diseases with regard to their aetiology and pathogenesis, ending up with a list of 1616 different conditions. Therefore, the trunk of the basis of medical classification presents two hubs: it is always the fifth branch which starts to ramify, demonstrating a further and broader perspective of classification. This differentiated form of classification has its origins in Buddhism but may be influenced by the medical achievements of Tibetan culture. Early Chinese Buddhist texts also deal with 404 diseases, but in these texts the four elements are as found in Byzantine medicine (earth, water, fire and wind) and stand for each group of 101 diseases (Unschuld 1985: 141).

Only half of the 404 diseases deal with humoral pathologies. The first 101 diseases according to individual humours are just roughly summarised in the Explanatory Treatise, but in Lozang Chödrak's text they are listed individually, divided into general (spyi) and specific (bye brag) conditions. The general forms of dyscrasia are subdivided into type (rigs) and location (gnas), and the specific conditions deal with specific forms of the humours, as each humour is differentiated in five subcategories, described already in the chapter five in the Explanatory Treatise on physiology. Therefore, there are 15 specific forms and another 30 relating to combinations of the humours. A comparative examination reveals that Lozang Chödrak's list of general dyscrasias follows the sequence given in the Instructional Treatise. The 101 diseases of the following branch of the main classification (II.5.2) are explained rudimentarily in the Explanatory Treatise and not at all in the Instructional Treatise. The main classes of humoral imbalances demonstrate the theoretical complexity of imbalances without any clinical examples. They are divided into 'self-founded' or independent (rang rgyud can; II.5.2.i) and 'connections with one another' or dependent conditions (gzhan rgyud can; II.5.2.ii). The 18 independent dyscrasias are listed with regard to six quantitative stages: increase, strong increase and strongest increase as well as decrease, strong decrease and strongest decrease. The category of dependent dyscrasias is subdivided into three branches: 'compounded' bi-humoral (ldan pa; II.5.2.ii), 'assembled' tri-humoral (vdus pa; II.5.2.ii) and 'dangerous' ones (bla gnyan; II.5.2.ii), 
the latter of which is another group of 27 complex conditions. The independent, compounded and assembled disorders amount to 74 diseases; added together with the 27 'dangerous' ones, they sum up to 101 dyscrasias, which are listed individually in Lozang Chödrak's text, including their quantitative stages. Moreover, in his commentary to the twenty-first chapter of the Explanatory Treatise on compounded medicines, he comes back to the list of 74 main diseases and gives pharmacological advice for each disorder. An example for the treatment of a bi-humoral, balanced dyscrasia is illustrated in the following description: 'Equal decrease of phlegm and bile: sweet increases phlegm and sour increases bile' (Blo-bzang-chos-grags 2005: 91/18-20). An example for the treatment of a trihumoral dyscrasia is 'decrease of wind will be increased by bitter and astringent (medicines), increased phlegm shall be cured by salty (ones), and increased bile shall be overcome by sweet taste' (Blo-bzang-chos-grags 2005: 94/21-3).

The following branch classifies pathologies according to another differentiated approach of nosology. The branch of 101 diseases classified according to their localisation is divided into 99 localisations on the body (lus) and two of the mind (sems). The first mental illness (smyo byed) may be regarded as a form of psychosis. The second one, brjed byed, is more difficult to translate but indicates some condition with signs of amnesia. However, it is not possible to equate the term with a disease in terms of the ICD system. The term is translated differently in the available dictionaries: Roerich suggests 'amnesia' (Roerich 1985 [V3]: 218), while according to Jäschke, rjed byed might mean '1) a demon that takes away the power of memory, also rjed byed kyi don. 2) epilepsy’ (Jäschke 2001 [1881]: 181). Dash (1994-2001: 163) suggests 'epilepsy', but Goldstein et al. (2001: 404) identify brjed byed with Alzheimer's disease. Common to all interpretations, however, whether absences, grand mal epilepsy (ICD G40-41) or various forms of dementia (ICD F00-F03), is some kind of amnesia.

The bodily conditions are subdivided topographically into five further categories: diseases of the upper (stod; II.5.3.ii.a), lower (smad; II.5.3.ii.b), outer (phyi; II.5.3.ii.c) and inner body (nang; II.5.3.ii.d), while the fifth category indicates widespread general physical afflictions (kun khyab thun mong; II.5.3.ii.e). The named afflictions are not necessarily well-defined diseases, since half of the defined leaves of the upper body are just body parts such as nose (sna), lips ( $m c h u$ ), teeth (so), tongue (lce), palate (rkan) and throat (gre ba). Some of the given leaves should be regarded as signs or symptoms rather than a disease. A good example is the delicate translation of the term dbugs mi bde ba, which literally means 'difficult breathing' or dyspnoea. As the physician Florian Ploberger already remarked critically (2012: $2010 \mathrm{n} 3$ ), many authors translate the term as asthma. In my opinion, the translation as asthma would only be correct if the respective author would use the term in its original meaning, as found in the ancient Greek term âsthma $(\tilde{\alpha} \sigma \theta \mu \alpha)$, which merely means 'to pant' or 'to breathe hard'. But if the word asthma is used to refer to the common biomedical condition of asthma bronchiale, a group of diseases classified as J45 in the modern ICD 10 system, the translation would be misleading because dyspnoea is also a 
characteristic symptom of chronic obstructive pulmonary disease (COPD, ICD J44), pulmonary emphysema (ICD J43) or pulmonary fibrosis, which again is variously classified according to diverse aetiologies.

Similarly, physical afflictions of the lower body are presented not only as signs or symptoms such as constipation (rtug vgags), urinary retention (gcin vgags) or dysuria (gcin snyi) but also as surprisingly concrete lesions such as haemorrhoids (gzhang vbrum; ICD K64) or anal fistula (mtshan bar rdol ba; ICD K60). Haemorrhoids are also mentioned in the Suśruta-samhitā, where they are called arśas. The Tibetan equivalent is a compounded term formed of rectum (gzhang) and a word used for grains, fruits or 'pox' (vbrum). The Tibetan term mtshan bar rdol $b a$ is less specific, compounded of genitals (mtshan) and to leak, to have holes or fistula (Jäschke 2001: 288). Usually it is translated as anal fistula, but it also could mean the rare occurrence of perineal fistula (Tsering Thakchö Drungtso and Tsering Dolma Drungtso 2005: 378). The 20 pathologies of the outer body are subdivided according to their tissue assignment into skin (pags pa), flesh (sha), channels $(r t s a)$ and bones (rus), listing clinical pictures which are difficult to define from a medical point of view. The pathologies of the skin are listed through the names of specific cutaneous conditions with metaphorical descriptions such as 'licked by a cow' (bas ldags [also bldags]) or 'ox sore' (glang shu). They also include venereal diseases. The section on flesh does not mainly deal with muscular problems, since the only specific names found in this passage are goitre $(l b a b a)$ and alterations of lymphoid tissue (rmen bu). Pathologies of the interior body are located in certain inner organs or are listed as signs and symptoms such as abdominal cramps (glang thabs), intestinal colic (rgyu gzer), diarrhoea ( $v k h r u$ $b a$ ), vomiting (skyug pa), tumour-like phenomenon (skran) or malignant ulcer (sur ya). The medical identification of the last two terms is extremely difficult and a delicate issue, because Tibetan medicine is often associated with an alternative treatment of cancer, as discussions on the classical term vbras demonstrate (Czaja 2011). I use the terms tumour and malignant (ulcer: sur ya) in their original meaning. The word tumor in Latin means 'swelling' and does not necessarily refer to a kind of neoplasm; and the word 'malignant' basically refers to something bad or difficult to handle (such as malignant hypertension) and not necessarily to a form of cancer.

The widespread general bodily conditions comprise a wide spectrum of syndromes, stages of pathological processes, morphological changes, infections, intoxications, wounds and rather abstract disturbances associated with planets and demons.

The 101 diseases classified according to type are divided into internal diseases (khong $\mathrm{nad}$; II.5.4.i), wounds or lesions (rma; II.5.4.i), heat [disorders] (tshad $p a$; II.5.4.i) and a group of disorders of diverse nature (thor bu; II.5.4.i). Many of the names given here have already been mentioned in the branch of classification according to the location, but here they are classified more with regard to their pathogenesis than their topography. The internal diseases deal with indigestion, on the one hand, and the resulting chronic conditions, on the other hand. Indigestion is again divided into new (gsar ba) and old complaints (rnying pa), 
whereas the first group is classified according to its nature (ngo bo), type (rigs), concomitants (grogs) and duration or stage ( $d u s)$. The pathology of the 23 chronic disorders resulting from indigestion is divided into five forms: tumorous formations (skran), effusions ( $d m u$ chu), oedema (vor), 'pale dropsy' (skya rbab) and emaciation (zad byed). Lesions are divided into endogenous or inherent (lhan gcig skyes $b a$ ) and exogenous or spontaneous lesions (lo bur ba). Examples of endogenous lesions are haemorrhoids and anal fistula (which were already mentioned in the category of diseases of the lower body) and testicular swelling (rlig blug $[$ rlugs]), which is also listed in the category of andropathies (i.e. male disorders). Within the branch of the location of general widespread diseases (II.5.3.ii.e) we find categories of lesions on the head ( $m g o$ rma), trunk (byang khog), neck (skye) or extremities (yan lag). Within the branch of the classification according to type, exogenous lesions are differentiated according to the type of injury, such as 'cut through' (rnam par bcad pa), 'hanging down' (vphyang ba), 'penetrated' (phug $p a)$, 'splintered' (gshags pa) or 'broken' (grugs pa). Endogenous lesions are also explained in great detail in chapters 63-70 of the Instructional Treatise and exogenous lesions in chapters $82-86$ respectively.

The classification of heat disorders or 'fevers' plays an important role in Tibetan medicine. In the classification presented according to type, 'cold' diseases do not play such an important role, but the cold types of condition are mainly associated with humoral pathologies. However, again, many of the various types of heat are listed within the branch of the location of general widespread diseases. Here, they are differentiated according to types such as immature ( $m a$ smin $\mathrm{pa}$ ), pronounced (rgyas pa), empty or exhausted (stongs pa), hidden or latent (gab pa), chronic (rnyings $p a$ ) and turbid heat/fever (rnyogs $p a$ ). The heat disorders are further classified with regard to their pathogenesis as spreading fever (vgrams tshad), disturbed fever (vkhrugs tshad), contagious diseases (rims nad) and fever due to intoxication (dug tshad). Chapters 12-27 of the Instructional Treatise explain the signs and symptoms and the respective therapy for each of these subgroups.

There is further a group of disorders of diverse nature which consists of 19 disorders that were already mentioned through different sub-branches of the branch of location, such as urinary retention and dysuria located in the lower body (II.5.3.ii.b) or diarrhoea and vomiting in the interior body (II.5.3.ii.d). However, the sequence given in the Tree of Nosology is almost the same as in the respective 19 chapters 44-62 in the Instructional Treatise. This group of disorders illustrates that Tibetan nosology considers elaborately a broad spectrum of different points of view, but it is hard to resist the impression that the lists within lists on which the Tree of Nosology is based are compiled to fulfil the required exact amount of the 101 disturbances listed in each of the four branches.

The final branch illuminates the 404 diseases of the other branches from the perspective of four different aetiologies. In the Explanatory Treatise, they are introduced only with one line each, but they are listed in a detailed manner by Lozang Chödrak. These are branches that classify diseases as: (1) being dependent on another [influence] (gzhan dbang can; II.5.5.i) and leading to death despite treatment; (2) imaginary diseases (kun rtags; II.5.5.ii) which can be caused by 


\section{Katharina Sabernig}

demons and are treated by rituals and sacrifices; (3) matured diseases (yongs grub II.5.5.iii) which are serious diseases that can be cured by treatment; and (4) simulated diseases (ltar snang; II.5.5.iv) - conditions that are deceptively similar to an illness but need no treatment, as they heal by themselves. After restructuring the first and second group in detail, Lozang Chödrak lists the essence of the third and fourth group in a nutshell. Then he ends with a remark which appears to be colloquial, and he seems to say that it would have been better to enumerate the traditional classification of these diseases individually, but that his text should nonetheless be sufficient, as if it was out of fear of using too many words (Blobzang-chos-grags 2005: 63/14-16). ${ }^{10}$

\section{Conclusion}

The Tree of Nosology as depicted in the inner courtyard of the medical college at Labrang Monastery is a visual aid intended to facilitate the understanding and memorisation of the various perspectives of disease classification in Tibetan medicine. The arboreal metaphor is ubiquitous in Tibetan medical culture, but it can be found as a helpful didactic tool in various medieval texts of neighbouring medical traditions as well. The aim of this chapter was to introduce the arboreal metaphor, to extract different Tibetan schemes of classifications of disease by highlighting them with some examples, and to discuss translations into a modern medical language. It turned out that numerous parallels to other medical traditions can be discovered, such as the polarity of hot and cold, the movement of humours and their connection to the elements or the topographical classification of pathological conditions. In many cases, the specific character of Tibetan disease names becomes clearer if the etymology of medical terminology is taken into consideration. A review of the linguistic history of Western medical terminology is often more promising for an understanding of traditional Tibetan terminology than a schematic approximation to modern pathologies found in the ICD system.

\section{Notes}

1 The present research has been subsidised by the Austrian Science Fund (project P22965-G21 and P26129-G21). The transliteration of Tibetan terms is based on the system attributed to Turrell V. Wylie, but with a small difference which corresponds to the long-established transliteration system in China (Jiang Di and Long Congjun 2010) and is also applied by the Staatsbibliothek in Berlin: instead of the apostrophe for the so-called va chung, ' $\mathrm{v}$ ' is written.

2 Among scholars, some colleagues argue that the term 'humour' or 'humoral pathology' should not be used in the case of Tibetan medicine or Āyurveda as it might be misleading and demonstrates a Eurocentric perspective. A further argument is that the 'humours' in Āyurveda and Tibetan medicine are not regarded as materially liquid. I use the term in a broader sense which also includes some subtle or energetic fluidity. The same problem comes up with the term 'biomedicine', which has been introduced to avoid the term 'western medicine'. Some scholars use 'established medicine' (see for a broader discussion: Adams et al. 2010: 112). 
3 With the exception of the sanguine mood, which derives from the Latin word for blood (sanguis), all the terms derive from Greek words. Nevertheless, the Greek term for blood plays an important role in modern 'biomedical' terminology, as haima is eponymous for the science of blood (haematology) including diseases such as haemophilia or signs such as haematuria (blood in urine) or hyperuricaemia (uric acid in the blood). Other modern medical terms are connected to the Greek humours: chole is namegiving for cholelithiasis, the professional name for gallstone; or cholecystitis indicates an inflammation of the gallbladder.

4 The first, second and fourth treatise are already available in English translations (Dash 1994-2001; Clark 1997; G.yu-thog Yon-tan-mgon-po 2008; Ploberger 2012 in German). Complete translations of all four treatises exist in Russian, Mongolian and Chinese.

5 Different editions of this set were published: Parfionovitch et al. (1992); Byams-pavphrin-las and Wang Lei (1994). More historical details on the development of politics and medical discussions may be found throughout Janet Gyatso's book Being Human in a Buddhist World (2015).

6 In my dissertation, which contains results of my project (P22965-G21), subsidised by the Austrian Research Fund, I was able to prove that the Labrang murals are based on Lozang Chödrak's text.

7 Although state-accredited contemporary education in Tibetan medicine is organised secularly, I heard several times of students who were able to learn the metric text by heart.

8 More information on the history of the Labrang murals and a comparison with the illustrations to the Blue Beryl can be found in my articles and dissertation on 'visualised medicine' (Sabernig 2012, 2013, 2014, 2017).

9 An image of the Tree of Nosology is included in Sabernig (2014, 2017).

10 vdivi dbye srol re re bzhin bgrang na legs pavi mchog mod kyang/vdi tsam gyis bris pas don rtogs par vgyur bas na de bzhin zhig yi ge [yi ger] vjigs pas de tsam mo.

\section{References}

Adams, V., Dongzhu, R. and Le, P. V. (2010) 'Translating Science: The Arura Medical Group at the Frontiers of Medical Research', in Craig, S., Cuomu, M., Garrett, F. and Schrempf, M. (eds.) Studies of Medical Pluralism in Tibetan History and Society: Proceedings of the Eleventh Seminar of the International Association for Tibetan Studies, Königswinter 2006. Beiträge zur Zentralasienforschung, Band 18. Halle: IITBS, 111-36.

Bkra-shis-dpal-ldan (1985) Sum cu pavi sdong vgrems blo gsal mgul rgyan: ram pa bkra shis dpal ldan gyis brtsa mas. Lha sa: Bod ljongs mi dmangs dpe skrun khang.

Blezer, H., Czaja, O. and Garrett, F. (2007) 'Brief Outlook: Desiderata in the Study of the History of Tibetan Medicine', in Schrempf, M. (ed.) Soundings in Tibetan Medicine: Anthropological and Historical Perspectives. Proceedings of the Tenth Seminar of the International Association for Tibetan Studies, 2003. Leiden/Boston: Brill, 427-38.

Blo-bzang-chos-grags [Dar-mo sman-rams-pa] (2005) 'Bshad rgyud kyi sdong vgrems legs bshad gser gyi thur ma', in Legs bshad gser gyi thur ma bkav phreng mun sel sgron $m e$. Bod kyi gso ba rig pavi gnav dpe phyogs bsgrigs dpe tshogs. Pe cin: Mi rigs dpe skrun khang, 1-143.

Blo-bzang-chos-grags [Dar-mo sman-rams-pa] (2017) Dpal ldan rtsa bavi rgyud dang bshad pavi rgyud kyi sdong vgrems dang rdevu vgrems gsal bshad = Zang yi li lun jie shuo [㶓医理论解说]. Lha sa: Xi zang ren min chu ban she.

Bolsokhoeva, N. (2016) 'Tibetan Medical Illustrations from Atsagat Medical College and Other Anatomical Achievements of the Buryat Lama and Physician D. Endonov', Curare 39(1), 6-21. 
Bstan-vdzin-don-grub (2005-8) Dpal ldan rgyud bzhi: dpe bsdur ma. 2 Vol. Pe cin: Krung govi bod rig pa dpe skrun khang (Rgyal khab krung lugs gso rig do dam cus mi rigs sman gzhung dpe sna dag bsgrigs).

Byams-pa-vphrin-las and Wang Lei (1994) Bod lugs gso rig rgyud bzhivi nang don bris cha ngo mtshar mthong ba don ldan = Tibetan Medical Thangka of the Four Medical Tantras. Translated into English by Cai Jingfeng. Lha sa: Bod ljongs mi dmangs Dpe skrun khang.

Clark, B. (1997) Die Tibeter Medizin: Die Geheimnisse der Heilkunst aus den Hochtälern des Himalaja. Translated by T. Dunkenberger. Bern: O. W. Barth Verlag.

Czaja, O. (2011) 'The Four Tantras and the Global Market: Changing Epistemologies of Drä (vbras) versus Cancer', in Adams, V., Schrempf, M. and Craig, S. (eds.) Medicine between Science and Religion: Exploration on Tibetan Grounds. New York/Oxford: Berghahn, 265-95.

Czaja, O. (2013) Medieval Rule in Tibet: The Rlangs Clan and the Political and Religious History of the Ruling House of Phag mo gru pa: With a Study of the Monastic Art of Gdan sa mthil. 2 Vol. Wien: Verlag der Österreichischen Akademie der Wissenschaften.

Dash, V. B. (1994-2001) Encyclopaedia of Tibetan Medicine: Being the Tibetan Text of Rgyud bzhi and Sanskrit Restoration of Amrta Hrdaya Aștāinga Guhyopadeśa Tantra and Expository Translation in English. 7 Vol. Indian Medical Science Series No. 23. New Delhi, India: Sri Satguru Publications.

Demaitre, L. (2012) 'The Isagoge and Five Other Texts of the Articella (1210-30?): Iohannitius (Hunayn ibn Ishaq al-Ibadi) and Others', in Sappol, M. (ed.) Hidden Treasure: The National Library of Medicine. Bethesda, MA/New York: National Library of Medicine/ Blast Books, 22-5.

Eckart, W. (2005) Geschichte der Medizin, 5. Korrigierte und aktualisierte Auflage mit 35 Abbildungen. Heidelberg: Springer.

Ehring, F. (1989) Hautkrankheiten: 5 Jahrhunderte wissenschaftlicher Illustration - Skin Diseases: 5 Centuries of Scientific Illustration. Stuttgart/New York: Gustav Fischer Verlag.

Gerl, R. and Aschoff, J. (2005) Die Medizinhochschule Tschagpori (lcags po ri) auf dem Eisenberg in Lhasa: Geschichte - Fakten - Zeitzeugen. Ulm: Fabri Verlag.

Goldstein, M., Shelling, T. and Surkhang, J. (eds.) (2001) The New Tibetan-English Dictionary of Modern Tibetan. Berkeley: University of California Press.

Gundert, B. (1998) 'Die Tabulea Vindobonensis als Zeugnis alexandrinischer Lehrtätigkeit um 600 n. Chr.', in Fischer, K.-D., Nickel, D. and Potter, P. (eds.) Text and Tradition: Studies in Ancient Medicine and Its Transmission Presented to Jutta Kollesch. Leiden/ Boston/Köln: Brill, 91-144.

Gyatso, J. (2015) Being Human in a Buddhist World: An Intellectual History of Medicine in Early Modern Tibet. New York: Columbia University Press.

Gyurme Dorje (1992) 'The Structure and Contents of the Four Tantras and Sangye Gyamtso's Commentary, the Blue Beryl', in Parfionovitch, Y., Gyurme Dorje and Meyer, F. (eds.) Tibetan Medical Paintings: Illustrations to the 'Blue Beryl' Treatise of Sangye Gyamtso (1653-1705), Vol. 1. London: Serindia Publications, 2-13.

G.yu-thog Yon-tan-mgon-po (2008) Bdud rtsi snying po yan lag brgyad pa gsang ba man ngag gi rgyud las rtsa bavi rgyud dang bshad pavi rgyud ces bya ba bzhugs so (The Basic Tantra and The Explanatory Tantra from the Secret Quintessential Instructions on the Eight Branches of the Ambrosia Essence Tantra). Edited by Dawa, Translated by T. Paljor. Dharamsala: Men-Tsee-Khang.

Jacob-Friesen, H. (2007) 'Von der Psychomanie zum Psychothriller. Die Sieben Todsünden in der Kunst', in Bellebaum, A. and Herbers, D. (eds.) Die sieben Todsünden: über Laster und Tugenden in der modernen Gesellschaft. Münster: Aschendorf Verlag, 29-85. 
Jäschke, H. A. (2001 [1881]) A Tibetan-English Dictionary. Richmond: Curzon Press.

Jampal Kunzang (1973) Tibetan Medicine. New Series, vol. 24. London: The Wellcome Institute of the History of Medicine.

Jiang Di (江荻) und Long Congjun (龙从军) (2010) 藏文字符研究: 母, 读音, 编码, 字 频,排序,图形,拉丁字母转写规则研究 (= On Characters of Tibetan Writing System: Alphabetic Characters, Pronunciations, ISO Codes, Frequencies, Sorting Orders, Picture Symbols, and Transliterations). Beijing: 社会科学文献出版社.

Krafft, F. (2006) 'Elements, Theories of the', in Cancik, H. and Schneider, H. (eds.) Brill's New Pauly, Antiquity Volumes. Online edition. (http://dx.doi.org.500326584newpauly. erf.sbb.spk-berlin.de/10.1163/1574-9347_bnp_e329060) (Accessed 30 January 2018).

Kuriyama, S. (1999) The Expressiveness of the Body and the Divergence of Greek and Chinese Medicine. New York: Zone Books.

Liebeskind, C. (1995) 'Unani Medicine of the Subcontinent', in Van Alphen, J. (ed.) Oriental Medicine: An Illustrated Guide to the Asian Arts of Healing. London: Serindia Publications, 39-65.

Lorenzen, U. and Noll, A. (1992) Die Wandlungsphasen der traditionellen chinesischen Medizin. Band 1: Wandlungsphase Holz. München: Müller und Steinicke.

Meyer, F. (1992) 'Introduction: The Medical Paintings of Tibet', in Parfionovitch, Y., Gyurme Dorje and Meyer, F. (eds.) Tibetan Medical Paintings: Illustrations to the 'Blue Beryl' Treatise of Sangye Gyamtso (1653-1705). Vol. 1. London: Serindia Publications, $2-13$.

Meyer, F. (1995) 'Theory and Practice of Tibetan Medicine', in Van Alphen, J. (ed.) Oriental Medicine: An Illustrated Guide to the Asian Arts of Healing. London: Serindia Publications, 109-43.

Meyer, F. (2003) 'The Golden Century of Tibetan Medicine', in Pommaret, F. (ed.) Lhasa in the Seventeenth Century: The Capital of the Dalai Lamas. Leiden/Boston: Brill, 99-117.

Militarev, A. (2010) The Jewish Conundrum in World History. Boston: Academic Studies Press.

Mkhyen-rab-nor-bu and Byams-pa-phrin-las (1987) Gso rig rgyud bzhivi sdong vgrems vdod vbyung nor buvi mdzod. Pe cin: Mi rigs dpe skrun khang.

Nguyen Van Nghi (1996-97) Hoang Ti Nei King So Ouenn. 2 Vol. Uelzen: MedizinischLiterarische Verlagsgesellschaft. Second edition.

Nutton, V. (ed.) (2002) The Unknown Galen. London: Institute of Classical Studies, School of Advanced Study, University of London.

Nutton, V. (2006) 'Humoral Theory', in Cancik, H. and Schneider, H. (ed.) Brill's New Pauly, Antiquity Volumes. (http://dx.doi.org.500326584newpauly.erf.sbb.spk-berlin. de/10.1163/1574-9347_bnp_e15208640) (Accessed 30 January 2018).

Pad-ma-dkar-po [Blo-gsal-dbang-po] (2007) 'Rgyud bzhivi vgrel ba gzhan la phan pavi gter', in Bshad pavi rgyud kyi levu nyi shu pa sman gyi nus pa bstan pavi tshig gi don gyi vgrel ba mes povi dgongs rgyan zhes bya ba bzhugs so. Rgyud bzhivi vgrel ba gzhan la phan pavi gter. Bod kyi gso ba rig pavi gnav dpe phyogs bsgrigs dpe tshogs 52 . Pe cin: Mi rigs dpe skrun khang.

Parfionovitch, Y., Gyurme Dorje and Meyer, F. (eds.) (1992) Tibetan Medical Paintings: Illustrations to the 'Blue Beryl' Treatise of Sangye Gyamtso (1653-1705). 2 Vol. London: Serindia Publ.

Ploberger, F. (ed.) (2012) Wurzeltantra und Tantra der Erklärungen der Tibetischen Medizin [Deutsche Übersetzung basierend auf der Men-Tsee-khang Publikation (2008) von Ursula Derx und Florian Ploberger]. Schiedlberg, Austria: Bacopa.

Pormann, P. and Savage-Smith, E. (2007) Medieval Islamic Medicine. Washington, DC: Georgetown University Press. 


\section{Katharina Sabernig}

Priya Vrat Sharma (ed.) (2000) Suśruta-saṃhitā. Vol. 2. Haridas Ayurveda Series 9/2. Varanasi: Chaukhambha Visvabharati.

Roerich, Y. N. (1985) Tibetan-Russian-English Dictionary. Tibetsko-russko-angliiskii slovar', 11 Vol. Nauka Vol. 3. Moskva: Izdat.

Sabernig, K. (2012) 'On the History of the Murals in the Medical College at Labrang Monastery', Asian Medicine 7(2), 358-83.

Sabernig, K. (2013) 'Tibetan Medical Paintings Illustrating the Bshad rgyud: A Comparison of the Classical Thangka Set and Murals in the Medical College in Labrang Monastery', Zentralasiatische Studien 42, 61-82.

Sabernig, K. (2014) 'Medical Murals at Labrang Monastery', in Hofer, T. (ed.) Bodies in Balance: The Art of Tibetan Medicine. New York/Seattle: Rubin Museum of Art/University of Washington Press, 221-5.

Sabernig, K. (2017) Visualisierte Heilkunde: Eine medizinanthropologische Studie zur Identifizierung der Wandbilder der medizinischen Fakultät des Klosters Labrang. $\mathrm{PhD}$ Dissertation. University of Vienna (https://ubdata.univie.ac.at/AC14498862).

Sappol, M. (ed.) (2012) Hidden Treasure: The National Library of Medicine. Bethesda, MA/New York: National Library of Medicine/Blast Books.

Savage-Smith, E. (2002) 'Galen's Lost Ophthalmology and the Summaria Alexandrinorum', in Nutton, V. (ed.) The Unknown Galen. London: Institute of Classical Studies, School of Advanced Study, University of London, 121-38.

Schuh, D. (1973) Tibetische Handschriften und Blockdrucke sowie Tonbandaufnahmen Tibetischer Erzählungen: Teil 5: Verzeichnis Orientalischer Handschriften in Deutschland. Wiesbaden: Franz Steiner Verlag.

Steinert, U. (2016) 'Körperwissen, Tradition und Innovation in der babylonischen Medizin', Paragrana 25(1), 195-254.

Taube, M. (1981) Beiträge zur Geschichte der medizinischen Literatur Tibets. Sankt Augustin: VGH Wissenschaftsverlag.

Tsering Thakchö Drungtso [Tshe-ring-thag-gcod Drung-vtsho] und Tsering Dolma Drungtso [Tshe-ring-sgrol-ma Drung-vtsho] (2005) Bod lugs sman rtsis kyi tshig mdzod bod dbyin shan sbyar = Tibetan-English Dictionary of Tibetan Medicine and Astrology. Revised and enlarged edition. Dharamsala: Drungtso Publication.

Tsyrempilov, N. and Vanchikova, T. (2004) Annotated Catalogue of the Collection of Mongolian Manuscripts and Xylographs M1 of the Institute of Mongolian, Tibetan and Buddhist Studies of Siberian Branch of Russian Academy of Sciences. CNEAS Monograph Series No. 17. Sendai: Center for Northeast Asian Studies, Tohoku University.

Unschuld, P. U. (1985) Medicine in China: A History of Ideas. Berkeley/Los Angeles/New York: University of California Press.

Unschuld, P. U. and Tessenow, H. (2011) Huang Di nei jing su wen: An Annotated Translation of Huang Di's Inner Classic: Basic Questions: Volume I Chapters 1 through 52. In Collaboration with Zheng Jinsheng. Berkeley/Los Angeles: University of California Press.

Van Bussel, G. and Steinmann, A. (2011) Wald, Baum, Mensch: Eine Ausstellung des Museums für Völkerkunde. Wien: Kunsthistorisches Museum.

Wilson, E. J. and Dinkha, S. (2010) Hunain Ibn Ishaq's 'Questions on Medicine for Students': Transcription and Translation of the Oldest Extant Syriac Version (Vat.Syr.192). Citta del Vaticano: Bibliotheca Apostolica Vaticana.

Yang Ga (2010) The Sources for the Writing of the 'Rgyud-bzhi', Tibetan Medical Classic. PhD Dissertation. Cambridge, MA: Harvard University Press. 
Ye-shes-bzang-po [Gtsang-sman] (2007) 'Gtsang sman sdong grel țîkkā mun sel gsal ba'i sgron me', in Gtsang sman pavi sman yig phyogs bsgrigs. Bod kyi gso ba rig pavi gnav dpe phyogs bsgrigs dpe tshogs. Pe cin: Mi rigs dpe skrun khang, 132-54.

Yoeli-Tlalim, R. (2010) 'On Urine Analysis and Tibetan Medicine's Connections with the West', in Craig, S., Cuomu, M., Garrett, F. and Schrempf, M. (eds.) Studies of Medical Pluralism in Tibetan History and Society: Proceedings of the Eleventh Seminar of the International Association for Tibetan Studies, Königswinter 2006. Beiträge zur Zentralasienforschung, Band 18. Halle: IITBS, 111-36.

Yoeli-Tlalim, R. (2013) 'Central Asian Mélange: Early Tibetan Medicine from Dunhuang', in Dotson, B., Iwao, K. and Takeuchi, T. (eds.) Scribes, Texts, and Rituals in Early Tibet and Dunhuang: Proceedings of the Third Old Tibetan Studies Panel Held at the Seminar of the International Association for Tibetan Studies, Vancouver 2010. Wiesbaden: Dr. Ludwig Reichert Verlag, 53-60. 


\section{Appendix}

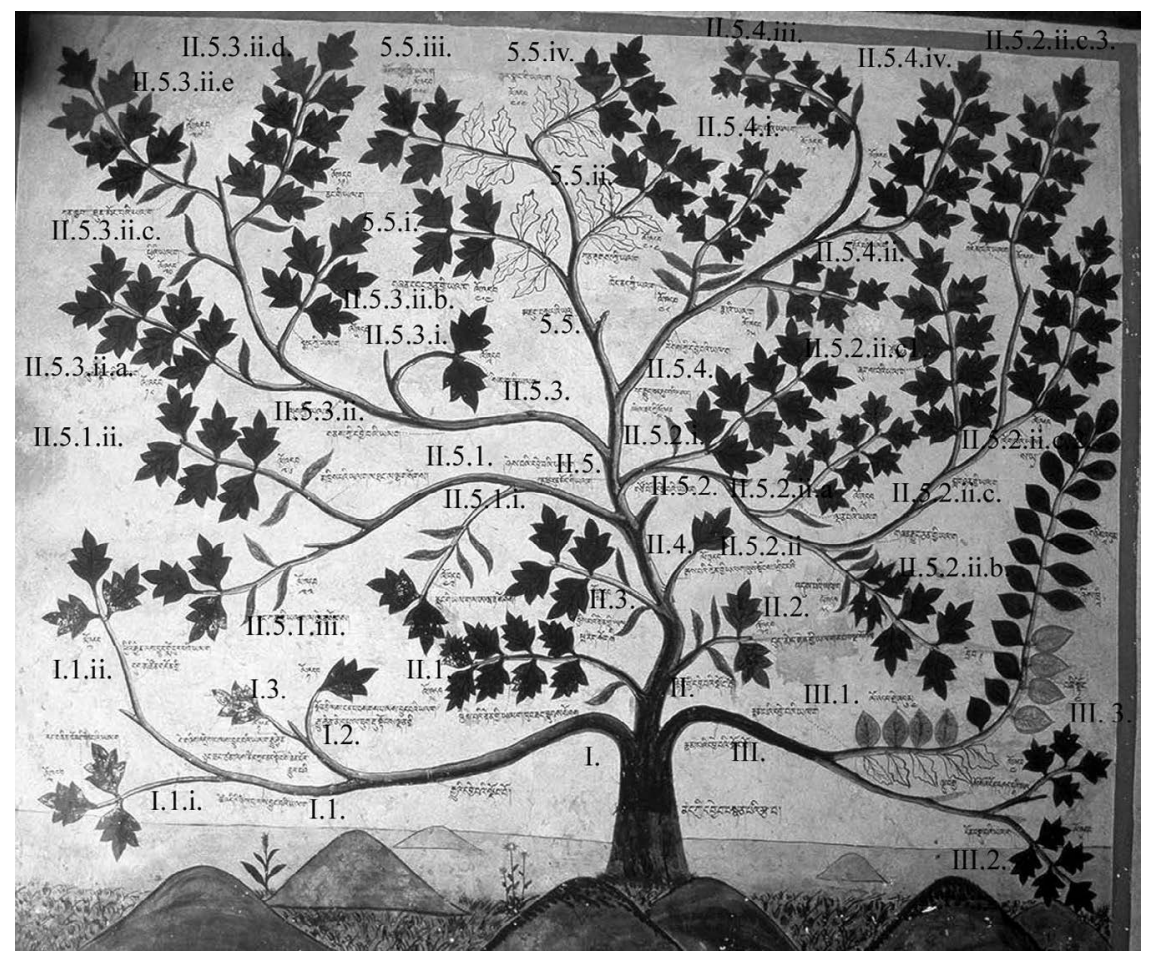

Figure 10.2 The Tree of Nosology

Source: Photograph: K. Sabernig

\section{The Tree of Nosology}

The Root of the Doctrine on the Classification of Diseases (nad kyi dbye ba bstan pavi rtsa ba)

I) Trunk of the classification of the cause (rgyuvi dbye bavi sdong bo) 
I.1) Branch of the occurrence of the humours at this lifetime (tshe vdivi nyes ba las byung bavi yal ga [tshe vdivi nyes pa las byung bavi yal ga])

I.1.i) Branch of the inner disposition for humoral pathologies: 3 leaves (rang bzhin khong gi nyes pavi yal ga // lo vdab 3 [ rang bzhin khong gi nyes bavi yal ga])

I.1.ii) Branch of the sudden emergence (of disease) due to external trigger factors: poisons, ghosts, weapons: 3 leaves (phivi rkyen las byung glo bur pavi yal ga dug mtshon gdon gyi // lo vdab 3 [phivi rkyen las byung glo bur bavi yal ga dug mtshon gdon gyi])

I.2) Branch of the occurrence (of disease) due to the accumulation of former bad deeds. [Leaf] of intense suffering where neither cause nor trigger factors are present: 1 leaf (sngon gyi las ngan pa bsags pa las byung bavi yal ga rgyu rkyen med pa la zug rngu stobs ldan gyi // lo $v d a b$ 1)

I.3) Branch of the occurrence (of disease) due to the mixing of the two [above]. Leaf of diseases whose strength is also enhanced by only minor causes and triggers (de gnyis vdres ba las byung bavi yal ga rgyu rkyen cung zad tsam las med kyang nad stobs chen por gyur pavi // lo vdab 1 de gnyis vdres las byung bavi yal ga rgyu rkyen cung zad tsam las med kyang nad stobs chen por gyur bavi)

II) Trunk of the classification of the base (rten gyi dbye bavi sdong bo)

II.1) Branch of the category of men: testicles, semen reduction, etc.: 18 leaves (skyes pavi rten gyi yal ga ku ba zad rlugs sogs // lo vdab 18 [skyes buvi rten gyi yal ga ku ba zad blugs sogs])

II.2) Branch of the category of women: five uterine [diseases] etc.: 32 leaves (bud med rten gyi yal ga mngal lnga sogs // lo vdab 32)

II.3) Branch of the category of children: detailed and cursory, etc.: 24 leaves (byis pavi rten gyi yal ga phra rags sogs // lo vdab 24 [byis bavi rten gyi yal ga phra rags sogs])

II.4) Branch of the category of (old) age: reduction of physical strength: 1 leaf (rgas pavi rten gyi yal ga lus stobs vgrib pavi // lo vdab 1)

II.5) Branch of the widespread, general [diseases] (kun khyab thun mong gi yal ga [kun khyab thun mong bavi yal ga])

II.5.1) Branch of humoral classification (nyes bavi dbye bavi yal ga)

II.5.1.i) Branch of wind: 'blockage in the lower part of the body', etc.: 42 leaves (rlung gi yal ga la a wa rta sogs // lo vdab 42

II.5.1.ii) Branch of bile: 'confluent', etc.: 26 leaves (mkhris pavi yal ga la thang la lhag sogs // lo vdab 26)

II.5.1.iii) Branch of phlegm: 'epicastric discomfort', etc.: 33 leaves (bad kan gyi yal ga la lhen sogs // lo vdab 33) 
II.5.2) Branch of the main classification (gtso bo dbye bavi yal ga [gtso bovi dbye bavi yal ga])

II.5.2.i) Branch of self-founded (conditions): increase and decrease: 18 leaves (rang rgyud can rkyang bavi yal ga vphel zad kyi // lo vdab 18)

II.5.2.ii) Branch of the connections with one another (gzhan rgyud can gyi yal ga)

II.5.2.ii.a) Branch of the 'compounded' (conditions): 18 leaves (ldan pavi yal ga // lo vdab 18)

II.5.2.ii.b) Branch of 'assembled' [humoral pathologies]: 38 leaves (vdus pavi yal ga // lo vdab 38)

II.5.2.ii.c) Branch of danger (bla gnyan gyi yal ga)

II.5.2.ii.c.1) Branch of (the points of) entry: 9 leaves (zhugs pavi yal ga // lo vdab 9)

II.5.2.ii.c.2) Branch of the 'rebelling' (conditions): 9 leaves (log pavi yal ga // lo vdab 9)

II.5.2.ii.c.3) Branch of coming together: 9 leaves (vdom pavi yal ga // lo vdab 9)

II.5.3) Branch of classification according to localisation (gnas kyi dbye bavi yal ga)

II.5.3.i) Branch of the mind: 2 leaves (sems kyi yal ga // lo $v d a b 2$ )

II.5.3.ii) Branch of the body (lus kyi yal ga)

II.5.3.ii.a) Branch of the upper body: 18 leaves (lus stod kyi yal ga // lo vdab 18)

II.5.3.ii.b) Branch of the lower [body]: 5 leaves (smad kyi yal ga // lo vdab 5)

II.5.3.ii.c) Branch of the outer [body]: 20 leaves (phyivi yal ga // lo vdab 20)

II.5.3.ii.d) Branch of the inner [body]: 19 leaves (nang gi yal ga // lo vdab 19)

II.5.3.ii.e) Branch of the widespread, general [diseases]: 37 leaves (kun khyab thun mong pavi yal ga // lo vdab 37)

II.5.4) Branch of the classification according to type (rigs kyi dbye bavi yal ga)

II.5.4.i) Branch of internal diseases: 48 leaves (khong nad kyi yal ga // lo vdab 48)

II.5.4.ii) Branch of wounds: 15 leaves (rmavi yal ga // lo vdab 15)

II.5.4.iii) Branch of heat ('fever'): 19 leaves (tshad pavi yal ga // lo vdab 19)

II.5.4.iv) Branch of diverse [diseases]: 19 leaves (thor bavi yal ga // lo vdab 19) 
II.5.5) Branch of conclusion (mjug bsdu pavi yal ga)

II.5.5.i) Branch of other dependent [diseases]: 404 leaves (gzhan dbang can gyi yal ga // lo vdab 404)

II.5.5.ii) Branch of the imaginary [diseases]: 404 leaves ( $k u n$ rtags kyi yal ga // lo vdab 404)

II.5.5.iii) Branch of the matured [diseases]: 404 leaves (yongs grub kyi yal ga // lo vdab 404)

II.5.5.iv) Branch of the simulated [diseases]: 404 leaves (ltar snang gi yal ga // lo vdab 404)

III) Trunk of the classification according to kind (rnam pavi dbye bavi sdong bo)

III.1) Branch of the classification according to type (rnam pavi dbye bavi yal ga)

III.1.A) 100 times 100,000: 4 [leaves] (lo vdab the vbum 4)

III.1.B) 10 million: 9 [leaves] (bye ba 9)

III.1.C) 1 million: 7 [leaves] (sa ya 7 )

III.1.D) 200,000: 2 [leaves] (gnyis vbum 2)

III.1.E) 20,000: 2 [leaves] (nyis khri 2)

III.1.G) Four thousand: 4 [leaves] (bzhi stong 4)

III.1.F) Five hundred: 5 [leaves] (lnga brgya 5)

III.2) Branch of the summarised meaning: 5 leaves (don bsdu pavi yal ga // lo vdab 5)

III.3) Branch of the explanation of the individual meaning: 4 leaves (so sovi don bshad pavi yal ga // lo vdab 4) 